\title{
Study on a New Type of Exothermic Insulating Riser
}

\author{
Nengwei WANG ${ }^{1, \mathrm{a}, *}$ \\ School of Material Science and Engineering \\ Panzhihua University \\ Panzhihua, People's Republic of China. \\ e-mail: wnw_2008@163.com
}

\begin{abstract}
With the higher and higher requirement for the quality of casting and the continuous development of casting technology, sand mold riser, heat insulation riser and heat production riser produced by the traditional process produced cannot reach the requirements of feeding of casting due to a lot of shortcomings, such as the lack of heat production and poor heat preservation effect. Therefore, the research and development to the risers with the dual function of heat production and heat insulation have attracted considerable attention of the foundry industry.

In the paper, on the basis of consulting a large number of literatures, the majority of heat production and heat insulation risers are analyzed, and a large number of experiments are conducted. The raw materials and the specific ratio of heat production and heat insulation riser are preliminarily determined: with aluminum powder $(15 \% \sim 25 \%)$ and ferric oxide $(8 \% \sim 15 \%)$ as the heating materials, graphite $(5 \% \sim 10 \%)$ as the auxiliary heating material, sodium silicate as the binder, cenosphere $(35 \% \sim 45 \%)$ as thermal insulation material,cryolite $(0 \sim 5 \%)$ as the fluxing agent, tail slag $(5 \% \sim 12 \%)$ as aggregate and some ferric oxide, and potassium chlorate $(2 \% \sim 6 \%)$ and potassium nitrate $(2 \% \sim 5 \%)$ as oxidants.

By comparing the ignition time and secondary combustion time of the different ratios of raw materials, the choices are gradually optimized. Finally, new heat insulation riser is obtained, which ignition time is $20 \sim 40 \mathrm{~s}$, secondary combustion time is 10 30s.
\end{abstract}

Keywords-heat insulation riser sleeve; ignition time; secondary combustion; production process

\section{INTRODUCTION}

The operational principle of insulating and exothermic riser is controlling the loss of heat through the affect that the material generates and preserves the heat and enhances the temperature of the hot metal in the riser as well in order to prolong the time of concreting and improve the efficiency of feeding. Most of risers contain heat insulating materials such as cenospheres and expanded perlite and once the raw materials are mixed with adhesives, the heat insulating materials will be covered by the adhesive forming cribrate and meshy structure, which makes the skeleton has cribrate and disperse organization structure to improve the concentration of heat and control the loss of it. At the same time, the air in the cribrate structures is excellent insulator, which can isolate the heat interaction completely making hot metal be molten all the time so as to ensure the effect of feeding. Meantime, the exothermic materials react and release heat making the internal metals be liquid prominently to assure the foundry goods benefit a lot from the effect of feeding.

Usually, the insulating and exothermic riser is composed of heat insulating materials, exothermic materials, flame-resistant aggregates, regulators and adhesives. In addition, these components must satisfy the following requirements, great heat-insulating property, magnificent fire-resistant property, good chemical stability at a high temperature, enough dry and wet strength, environment-friendly, easy to purchase, cheap and extensive sources etc.

First, there are thoroughfare between the foundry good and the riser.

The hot metal in the riser can't inflow into the foundry to execute the feeding process without the thoroughfare. What's worse, the risers only can be installed at the last concrete position of the foundry to ensure it concretes in order and the thoroughfare has to run through the whole procedure. In the process of concreting, it's essential to guarantee the circulation of the feeding passageway, which depends on the speed of absorption of heat and its thickness. Thus, what's the feeding thoroughfare? The concretion of foundry is from the bottom and two sides to the center. Then, in the center, there are all hot metal and they are connected with the caky parts. Therefore, what it forms is called thoroughfare. Additionally, the hot metal can inflow to the concrete parts with the help of gravity.

Secondly, the time-use of concretion in the position feeding is less than that in the riser.

The time-use of concretion in the position of feeding is less than that in the riser. If not, the metal in the riser will become solid and don't have flowability. Eventually, it has no effect on the feeding procedure.

Thirdly, there is enough hot metal in the riser to feed.

There is enough hot metal in the riser to feed in case the process can't finish completely and perfectly.

\section{EXPERIMENTAL PROCESS}

In this experiment the raw material were selected to adopt including cenosphere, graphite powder, ferric oxide powder, aluminum powder, cryolite, potassium nitrate, potassium chlorate, tail slag and sodium silicate. And in a variety of performance based on a lot of good riser formula was put forward, such as table 1. 
TABLE I. THE COMPOSITION AND THE PROPORTION OF HEAT INSULATING RISER

\begin{tabular}{rccccccccc}
\hline & Hollow & Cryoli & Potassiu & Potassiu & Aluminit \\
Content & $\begin{array}{c}\text { microsphe } \\
\text { re }\end{array}$ & te & $\begin{array}{c}\text { m } \\
\text { nitrate. }\end{array}$ & $\begin{array}{c}\text { ferricoxi } \\
\text { chlorate }\end{array}$ & $\begin{array}{c}\text { Tailin } \\
\text { powder }\end{array}$ & $\begin{array}{c}\text { de } \\
\text { te } \\
\text { powde } \\
\text { g slag }\end{array}$ & $\begin{array}{c}\text { Sodium } \\
\text { silicate }\end{array}$ \\
\hline Wt.\% & $35 \sim 45$ & $0 \sim 5$ & $2 \sim 5$ & $2 \sim 6$ & $15 \sim 25$ & $8 \sim 15$ & $5 \sim 12$ & $5 \sim 10$ & $8 \sim 13$ \\
\hline
\end{tabular}

One of the components were changed and other components remained unchanged, the size of the sample for $\Phi 20 \mathrm{~mm} \times 20 \mathrm{~mm}$ was made, dried at $730^{\circ} \mathrm{C}$ in the furnace for ignition time and secondary combustion time, sample combustion phenomena were observed. The ignition time and secondary combustion time were observed to determine the total composition, and then the reasonable content as a fixed value of the next set of experiments was determined. Under this train of thought for an ingredient research, the most reasonable components were found out, finally the good formula was determined.

Experimental methods by controlling variable method were used to test, that was, the amount of change a set of Yuan, the other groups content was constant, under the same conditions, the same size of sample was made, through the same processing, it could be concluded that the final sample, lit in electric furnace, test of the ignition time and the second burning time and record. Ignition timing here was a time, starting from the sample into the stove to become red sample was close to burning up, the length of the time to measure the degree of delay response from the beginning. Secondary combustion time refers to a flame from the start until the flame is extinguished, the duration of this illustrates the calorific efficiency of high and low.

Mix all raw materials weighing, stir well, with a glass rod and adding suitable amount of sodium silicate and water, stir, weigh out 10 grams, the weight of a mold molding, made 10 grams of a small cylinder, each recipe to do 10 , in the $150{ }^{\circ} \mathrm{C}$ oven to dry for 24 hours, it could be concluded that the final sample, the two parallel samples at $730{ }^{\circ} \mathrm{C}$ in the electric stove, the error range was checked.

The cause of the temperature of $730{ }^{\circ} \mathrm{C}$ was chosen due to the rise in holding liquid metal, used for feeding when casting molding, to avoid the formation of shrinkage cavity. But placed in the riser of liquid metal will gradually be solidified because of its heat dissipating, so using hot riser with heat, keep the liquid metal solidification, the use of its heat preservation effect, in order to make the liquid metal inside the riser can keep the liquid state for a long time to extend the function of the feeding. And at about $730{ }^{\circ} \mathrm{C}$, liquid metal has a tendency to be on solidification, riser lit at about $730{ }^{\circ} \mathrm{C}$.

\section{ANALYSIS AND DISCUSSION}

\section{A. Influence of different formulas on ignition time and secondary combustion time}

1) Influence of aluminum powder on ignition time and secondary combustion time

Remain unchanged, and other components in the aluminium content in turn set at 15\%,17\%, 19\%, 21\%, 23\%, $25 \%$, and the spectrum pure cryolite content was $3 \%$, and in turn, change the content of cenosphere, to be kept the total amount was $100 \mathrm{~g}$.

The average ignition time and average secondary combustion time of different ice crystals were added, and the figure 1 and figure 2 were obtained.

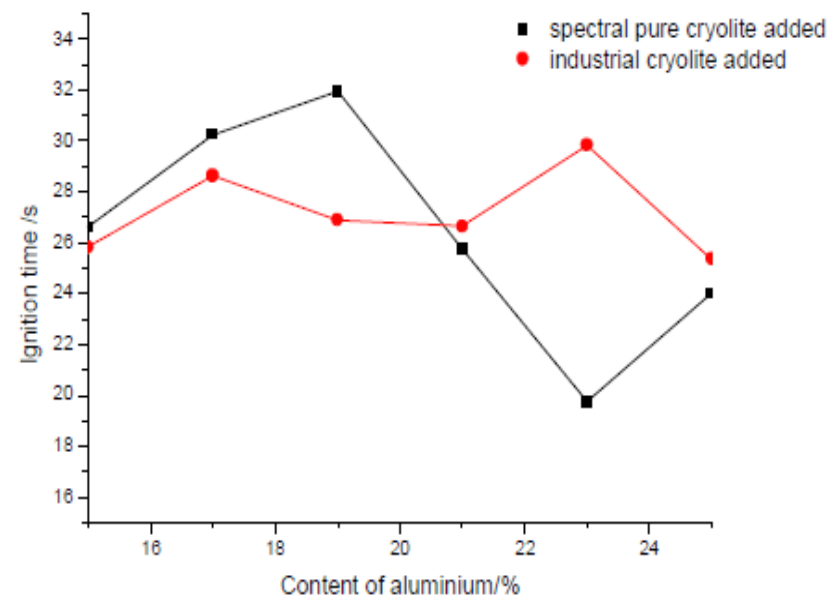

Figure 1. The relationship of the content of aluminium powder and ignition time.

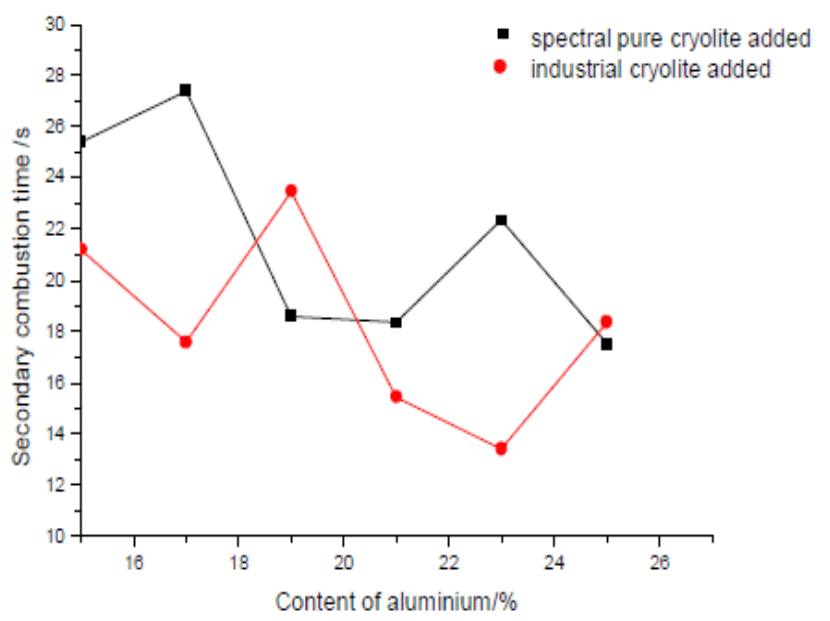

Figure 2. The relationship of the content of aluminium powder and secondary combustion time.

It could be seen from figure 1 that, with the addition of $3 \%$ for the spectral pure cryolite, the ignition time would rise and then decrease again with the increase of aluminum powder. When the content of aluminum powder was $19 \%$, the ignition time would be as long as $31.95 \mathrm{~s}$, then it would drop sharply. When the aluminum powder content reached $23 \%$, the ignition time would be as low as 19.75 s. 
When the industrial cryolite was added, the ignition time trend in both cases was approximately the same. With the increase in the content of aluminum powder, the ignition time would rise and then the trend would rise again. When the content of aluminum powder was $23 \%$, the ignition time was up to $29.84 \mathrm{~s}$ and then dropped sharply. When the content of aluminum powder reached $25 \%$, the ignition time was as low as $25.36 \mathrm{~s}$. It was indicated that the purity of cryolite had no effect on the fusible effect. It could be seen from figure 2 that, when adding the spectral pure crystal stone, the time of the secondary combustion time was $27.4 \mathrm{~s}$ and then dropped sharply when the content of aluminum powder was $17 \%$. When the content of aluminum powder was about $19 \%$, it tended to be gentle when the content of aluminum powder was $25 \%$, and the second time of combustion was the shortest, which was $17.5 \mathrm{~s}$. Combined the ignition time and the data of secondary combustion time, the content of aluminum powder was $18 \%$.

2) The influence of the change in the change of iron trioxide contention on Ignition time and secondary combustion time

The content of aluminum powder was fixed at $18 \%$, the content of iron trioxide was designed for $8 \%, 10 \%, 12 \%$, $14 \%$ and $16 \%$ respectively.

The effect of the change in the content of iron trioxide on the ignition time and the second combustion time was studied, and the average drawing of the two parallel patterns were used to draw the figure 3 and 4 .

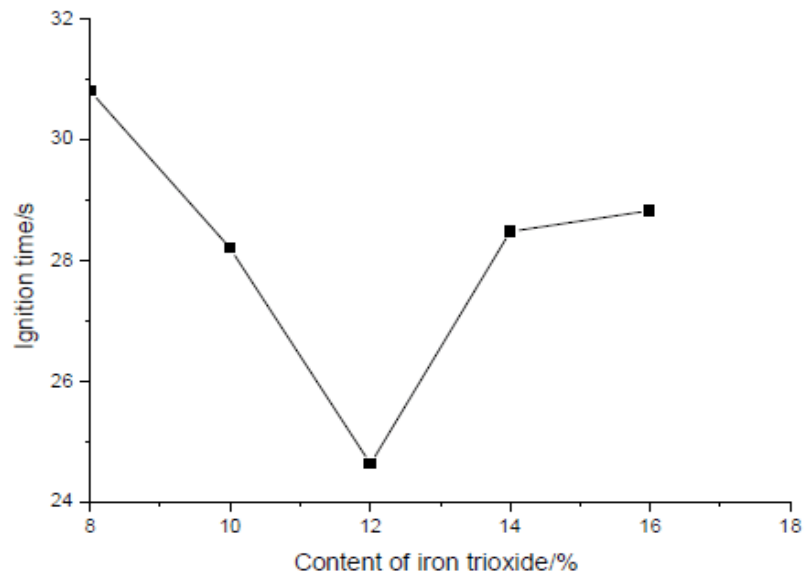

Figure 3. The relationship of the content of iron trioxide and ignition time.

As it could be seen from figure 3, with the increase of iron trioxide content, the ignition time was shortened and then increased. For $8 \%$, the ignition time was the longest, ignition time of $12 \%$ was the shortest, and the change trend was larger, from around $31 \mathrm{~s}$ to around $23 \mathrm{~s}$.

When the content of iron oxide was between $14 \%$ and $16 \%$, the change in ignition time was smaller, from $28.48 \mathrm{~s}$ to $28.825 \mathrm{~s}$, which had little effect on the ignition time of the experiment.

When the content of iron oxide was increased from $8 \% \sim 14 \%$, the secondary combustion time had two rise stages, from $15.7 \mathrm{~s}$ to $21.8 \mathrm{~s}$.
A slight decrease of $10 \% \sim 12 \%$, but not significant, began to decline when the iron oxide content reached $14 \%$, and at $16 \%$, the secondary combustion time was $18.9 \mathrm{~s}$.

Combined with ignition time and secondary combustion time analysis, the optimal content of trioxide should be $8 \%$.

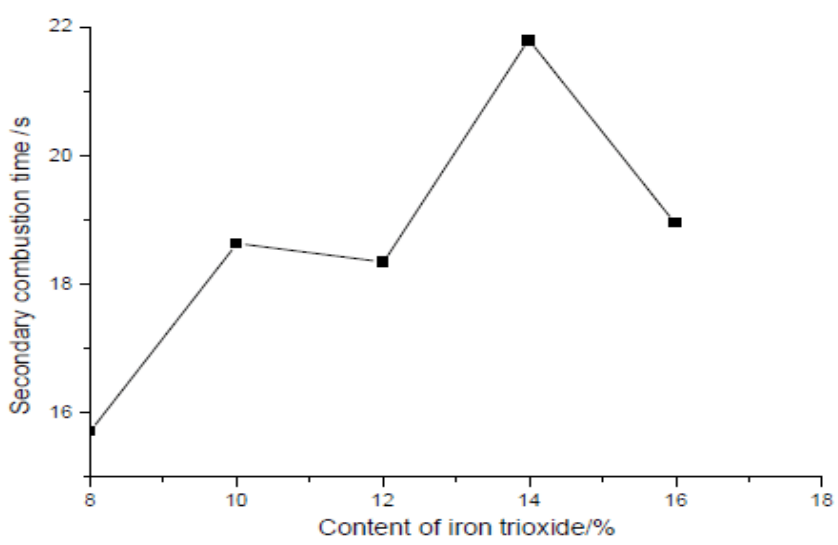

Figure 4. The relationship of the content of iron trioxide and secondary combustion time.

3) The change of potassium chlorate content impact on the ignition time and the secondary combustion time

The content of potassium chlorate was as follws: $15 \%$, $17 \%, 19 \%, 21 \%, 23 \%, 25 \%$, and the spectrum pure cryolite content was $3 \%$, and the content of cenosphere was changed in turn, so as to keep the total amount at $100 \mathrm{~g}$ and the formula was obtained.

The $\mathrm{KClO}_{3}$ impact on the ignition time and the secondary combustion time that were shown in figure 5 and figure 6 .

With the increase of the content of potassium chlorate, the ignition timing had a decreasing trend in general. When the content of potassium chlorate is 0 , the ignition time is very long and it can't meet the requirement of ignition. When the potassium chlorate content increases to $1 \%$, the ignition time reduced from $132.5 \mathrm{~s}$ to $19.2 \mathrm{~s}$, but it still couldn't meet the test requirement. When the content of potassium chlorate ranges was from $1 \%$ and $2 \%$, the ignition timing narrowed sharply, and it dropped from $107.5 \mathrm{~s}$ to $25.95 \mathrm{~s}$. Then as the content of potassium chlorate continuously increased, the ignition time decreased to $18.5 \mathrm{~s}$. This fully illustrated that the oxidizing agent played an important role in the thermite reaction of exothermic insulating riser. When the content of potassium chlorate was between $2 \%$ to $6 \%$, the change of the potassium chlorate content didn't have much effect on the ignition time.

As the content of potassium chlorate increase, secondary combustion was more and more voilently, and the smoke was more and more with a crackling sound. At the time that the potassium chlorate content was between $2 \%$ and $6 \%$, the secondary combustion time decreases in general. When the content was between $2 \%$ and $4 \%$, the time reduced drastically from $44 \mathrm{~s}$ to $22 \mathrm{~s}$. And it showed that the potassium chlorate played a vital role in the secondary combustion time, as well as it could enhance the thermit 
combustion and short the secondary combustion time. If he reduction rate of the content which was between $4 \%$ and $6 \%$ slowed down, the time reduced from $22 \mathrm{~s}$ to $18.25 \mathrm{~s}$. It showed that when the content of potassium chlorate was more than $4 \%$, the effect of the content on the secondary combustion time was much less.

In conclusion, potassium chlorate had a major impact on the ignition time and secondary combustion time, and it had good effect to improve the performance of insulating and exothermic riser. The best content of potassium chlorate was $3 \%$, so the choice of potassium chlorate content was $3 \%$.

4) The influence of the graphite content on ignition time and secondary combustion time

Fixing the content of other components remained unchanged, the content of graphite was changed, take 5\%, $6 \%, 7 \%, 8 \%, 9 \%, 10 \%, 12 \%, 14 \%, 16 \%$ of these quantities and test them, the samples were divided into 9 groups, 10 in each group. After drying, they were put into the electric furnace at $730^{\circ} \mathrm{C}$, the phenomena were observed and the ignition time and the secondary combustion time were tested.

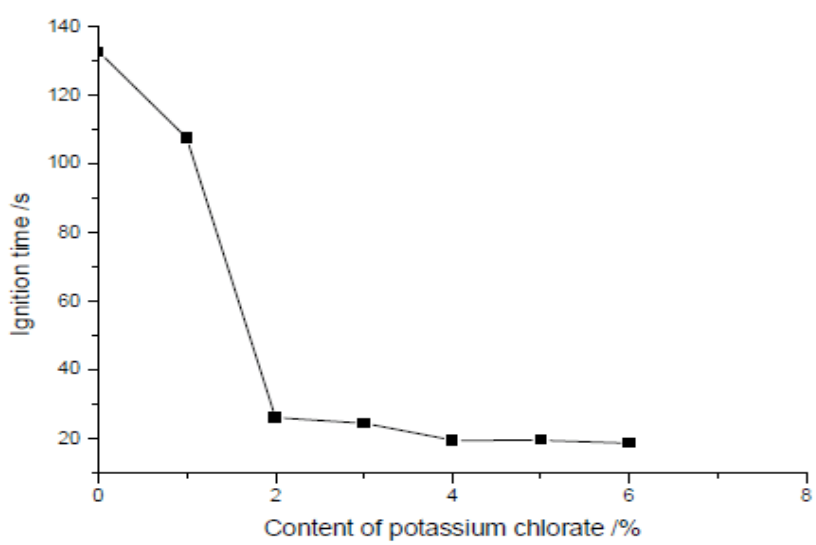

Figure 5. The relationship of the content of potassium chlorate and ignition time.

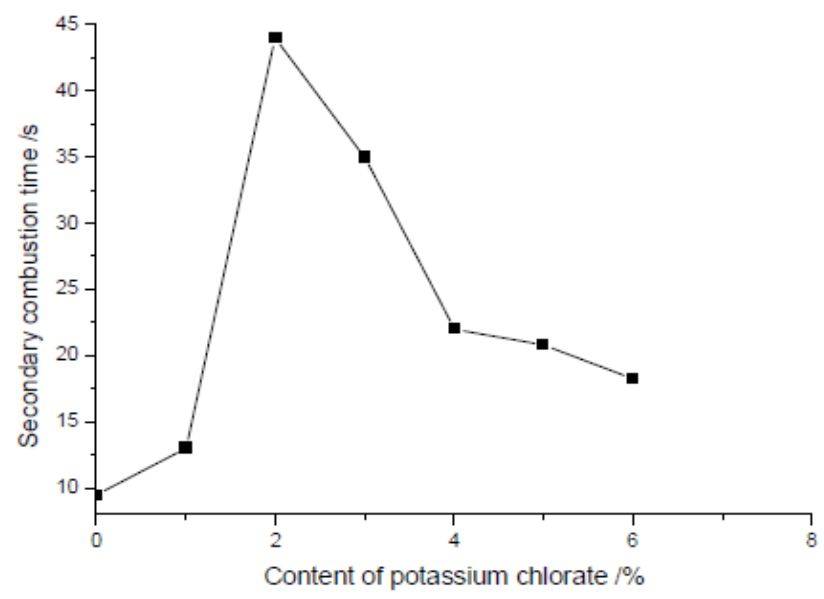

Figure 6. The relationship of the content of potassium chlorate and secondary combustion.

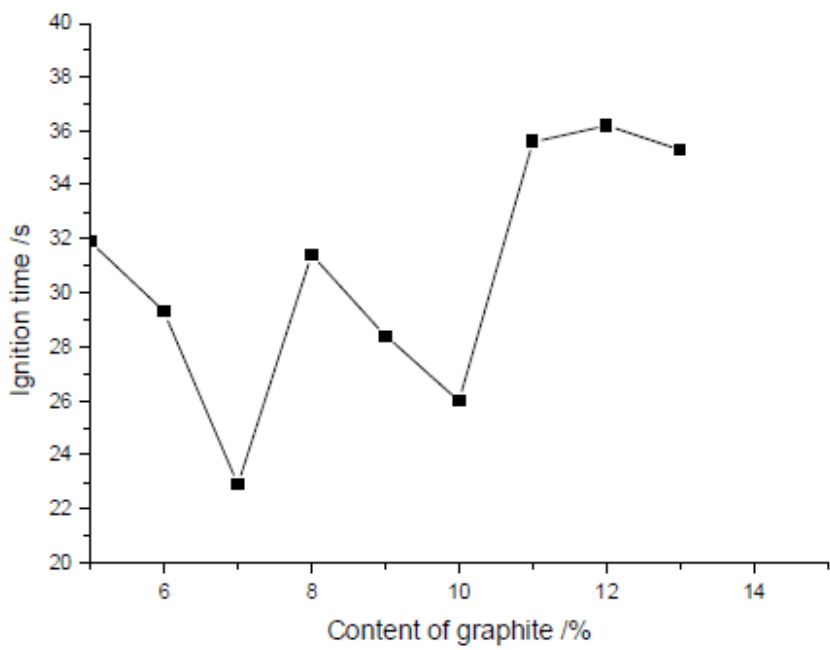

Figure 7. The relationship of the content of graphite and ignition time.

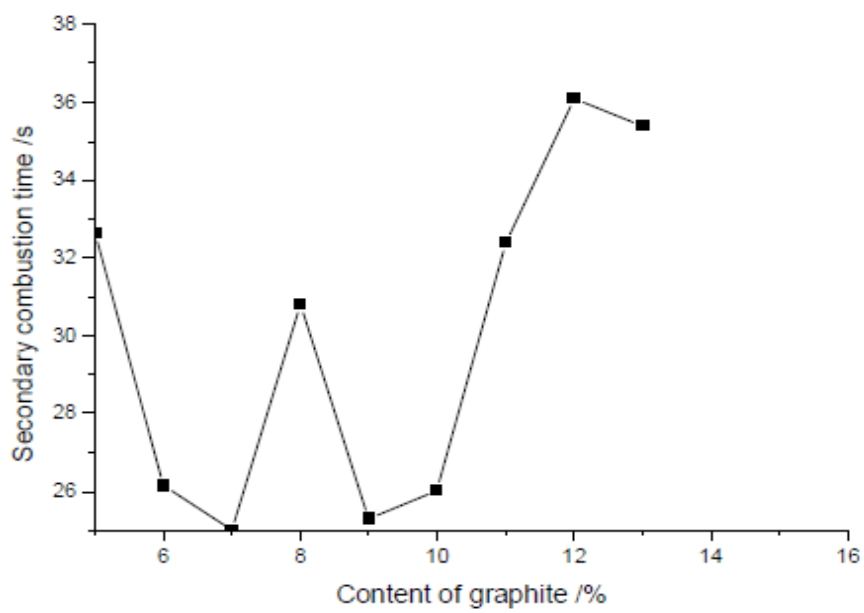

Figure 8. The relationship of the content of graphite and secondary combustion time.

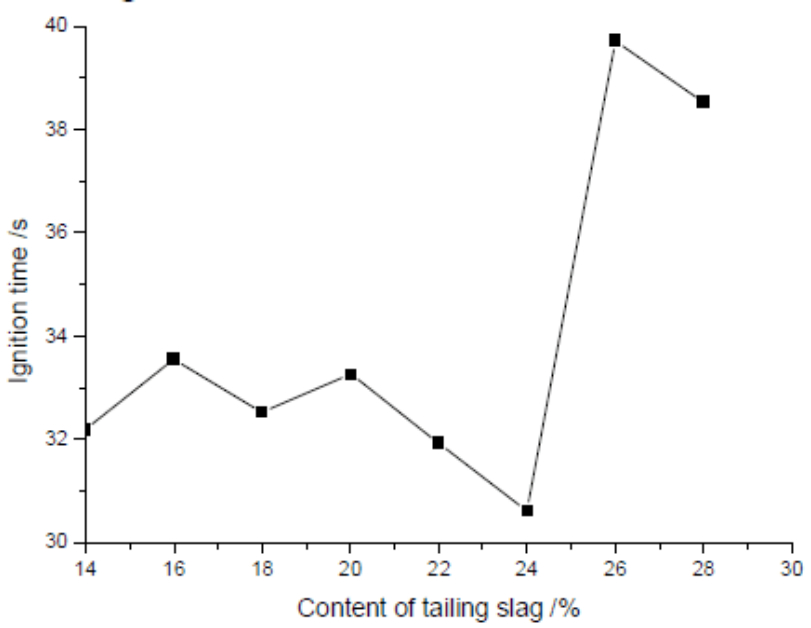

Figure 9. The relationship of the content of tailing slag and ignition time. 
Graphite powder influence on the ignition time and the secondary combustion time were shown in figure 7 and figure 8. It could be seen from figure 7 that with the increase of graphite content, the ignition time gradually decreased and then grown longer. The ignition time was the shortest at 9\%, and the ignition time was the longest at point $16 \%$. With the increase of the content of graphite powder, the ignition time varied greatly, and the rate of change was different. When the content of graphite powder was $6 \%$ 7\% and $9 \% \sim 12 \%$, the ignition time changed dramatically. When the content of graphite powder was 7\% 9\%, the ignition time had little change and a small decrease, from 9\% 10\%, increased sharply. So when the content of graphite powder was less than $12 \%$, less influence on the ignition time; when the content of graphite powder was more than $12 \%$, the influence of ignition time was greater.

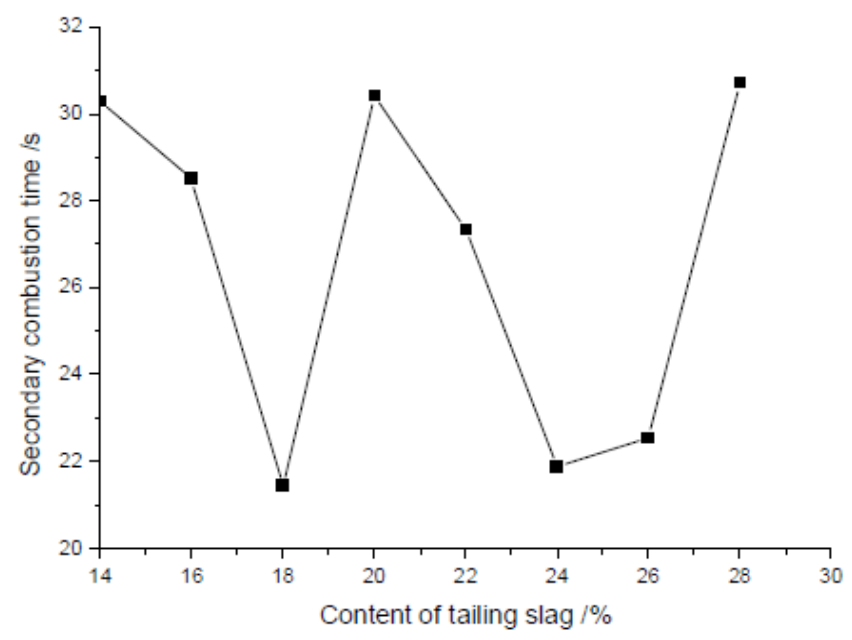

Figure 10. The relationship of the content of tailing slag and secondary combustion time.

5) The influence of tailing slag content change on ignition time and two combustion time.

The same fixed other component content, the content of tailings were changed for $14 \%, 16 \%, 18 \%, 20 \%, 22 \%, 24 \%$, $26 \%, 28 \%, 30 \%$ the amount of test, were divided into 9 group of sample preparation, observation and determination of ignition time and the two time burning time.

According to the average ignition time and the average two combustion time mapping, such as figure 9 and figure 10.

It could be seen from figure 9 that with the increase of tailing slag content, the ignition time always fluctuated upward and downward. However, when the tailings content was from $14 \%$ to $20 \%$, the fluctuation range was not very large, and the whole was slightly upward trend. It showed that when the tailings content was $14 \%$ to $20 \%$, the change of tailing had little effect on ignition time. When the slag content was from $24 \%$ to $28 \%$, the ignition time increased obviously, and rose from $30 \mathrm{~s}$ to $39.7 \mathrm{~s}$. In the end of slag content was $28 \%$ when the ignition time was $38.5 \mathrm{~s}$, but increased to $30 \%$ in tail slag content, the ignition phenomenon and before several groups were obviously different, about two and a half minutes before beginning a slow burning, and the burning was not obvious when the slag content was $30 \%$, no effect was on ignition test.

It could be seen from figure 10 that with the increase of tailing slag content, the two combustion time was "W" type, and the two combustion time maximum points were $14 \%$, $20 \%$ and $28 \%$, respectively, but their two combustion time were not the same, which were about 30 s or so, which were about three. The two burning time lowed were $12 \%$ and $24 \%$, respectively, which were about $21.5 \mathrm{~s}$ or so at $18 \%$. Similarly,when the tailing content was $30 \%$,the tailings didn't play a role in the two combustion test. According to the analysis above, the optimum content of tailing was $28 \%$.

\section{SUMMARY}

(1) The heat preservation Riser which made by ourselves have a large number of advantages. All the materials manufacture easily, easy to operate, wide varity of sources, price lowly and have better heat perservation performance. One part of this material is Fire-resistant aggregate, it is slag which made by Panzhihua industry, the slag have a widely resource and just cost a little.

(2) With the increase of Sodium Silicate, the strength increasing whatever before burning or after burning, add in some Sodium Silicate, the strength of after burning is better than before burning.

(3) The best efficient and low cost heat preservation riser formula is determined as follow: Cenosphere: $25 \%$, Graphite powder: $12 \%$, Iron oxide: $8 \%$, Aluminum powder: $18 \%$, Cryolite: $3 \%$, Potassium nitrate: $3 \%$, Potassium chlorate: $3 \%$, Tail slag: $28 \%$.

\section{ACKNOWLEDGMENT}

This work was financially supported by National Innovation Training Program for College Students (201411360005).

\section{REFERENCES}

[1] SONG Zhong-xun, YAN You-wei, etc. Influence of Sylvite Oxidizer on Properties of Exothermic/ Insulation Riser Sleeve. Equipments, Measurements and miscellanea. Vol.2(2007):p.76-p.80.

[2] WANG Min. Application of Heat Insulating Feeder in Foundry Production. Production Method \& Process. Vol.4(2005): p.51-p52.

[3] Zhang Nai-yun, Kou Feng-he. Application and Present Situation of Insulating Riser Sleeve and Exothermic Riser Sleeve. Machinery Manufacturing Engineer.Vol.10(1990):p.40-p.43.

[4] ZHAO Yu-hua, HAI Jie. A Study on Insulation Riser and Its Application in Cast Steel Items. Journal of Shenyang Institute of Aeronautical Engineering.Vol.17(2000):p.34-p.37.

[5] He Yuan, MA Min-tuan. Development of a New Heat Insulation Riser. Hot Working. Vol.12(2000):p.9-p.10.

[6] WEI Bing, TANG Yi-lin, ZHU Jian-xun. Application of Exothermic and Insulating Riser on the Casting Feeding Technology. Foundry Technology. Vol.29(2008):p.971-p.974.

[7] NIU Jin-xia. Hole Collar and Hole Collar Design.JOURNAL OF QINGHAI UNIVERSITY (NATURAL SCIENCE).Vol.6(2003):p60-p62.

[8] Chen Jian-ming. Study and Application of Cenosphere Insulating Sleeve. FOUNDRY.Vol.11(1986):p6-p8.

[9] ZHANG Shu-lan. A New Type of Cover Flux for Risers. Hot 
Working Process. Vol.2(1994):p.41-p.42.

[10] KOU Feng-he, LIU Fu-lai,etc. Research and Application of Insulation Riser Cenospheres. Journal of University of Science and Technology Beijing. Vol.12(1990):p.227-p.232.

[11] WANG Min. Application of Heat Insulating Feeder in Foundry Production. Production Method \& Process. Vol.4(2005): p.51-p52.

[12] LI Jun-ru, ZHANG Ming. Experimental Study on the Heat Riser
Sleeve. Shanxi Machinery. Vol.1(1994):p.25-p.28.

[13] Zhang lin, Guan Jun-sheng, Chen Ji-zhi. Research on the Property of Exothermic Insulating Riser. DEVELOPMENT AND APPLICATION OF MATERIALS, Vol.2(2009):p77-p78.

[14] QUAN Bei-ping, XU Hong, GU Hong-chen, etc. Progress in Research and Application for Hollow Micro Beads of Fly Ash. Industrial Minerals and Processing.Vol.11(2003):p.30-p.33. 